\title{
Does orthogonalization really purge equity based property valuations of their general stock market influences?
}

Article

Accepted Version

Brooks, C. and Tsolacos, S. (2000) Does orthogonalization really purge equity based property valuations of their general stock market influences? Applied Economics Letters, 7 (5). pp. 305-309. ISSN 1466-4291 doi:

https://doi.org/10.1080/135048500351447 Available at https://centaur.reading.ac.uk/35975/

It is advisable to refer to the publisher's version if you intend to cite from the work. See Guidance on citing.

Published version at: http://dx.doi.org/10.1080/135048500351447

To link to this article DOI: http://dx.doi.org/10.1080/135048500351447

Publisher: Taylor \& Francis

All outputs in CentAUR are protected by Intellectual Property Rights law, including copyright law. Copyright and IPR is retained by the creators or other copyright holders. Terms and conditions for use of this material are defined in the End User Agreement.

www.reading.ac.uk/centaur 
Central Archive at the University of Reading

Reading's research outputs online 
This is an Author's Accepted Manuscript of an article published in Applied Economics Letters (2000) [copyright Taylor \& Francis], available online at: http://www.tandfonline.com/10.1080/135048500351447 


\section{Does Orthogonalisation Really Purge Equity-Based Property Valuations of their General Stock Market Influences?}

Chris Brooks (corresponding author), ISMA Centre, PO Box 242, The University of Reading,

Whiteknights, Reading RG6 6BA; e-mail: C.Brooks@reading.ac.uk

and

Sotiris Tsolacos, Centre for Spatial and Real Estate Economics,

Department of Economics, University of Reading

8 June 1998

\section{Summary}

This paper uses a recently developed nonlinear Granger causality test to determine whether linear orthogonalization really does remove general stock market influences on real estate returns to leave pure industry effects in the latter. Our results suggest that there is no nonlinear relationship between the US equity-based property index returns and returns on a general stock market index, although there is evidence of nonlinear causality for the corresponding UK series.

J.E.L. Classifications: C32, C52

Keywords: nonlinear Granger causality, orthogonalization, stock market returns, real estate returns 


\section{Introduction}

A number of recent studies have sought to examine the properties and the performance of returns on real estate assetbacked public companies. This research work aims to identify the forces which drive real estate markets and explain the variation in real estate returns through time. These forces reflect trends in the real and monetary sectors of the economy and general stock market influences. As a result, central to such research is the study of the relationship between the stock market, the macroeconomy, and real estate returns. There are broadly two categories of real estate data that could plausibly be employed for this purpose. The first are appraisal-based series, such as the NCREIF property index for the US and the JLW index for the UK ${ }^{\mathrm{i}}$. However, a number of researchers have argued that the quality of appraisal-based data is poor in terms of its reflection of the true state of the property market at that particular point in time due to appraisal-induced price smoothing (see, for example Gyourko and Keim, 1992, or Geltner, 1989, Chan et al., 1990). This data feature is partly attributable to subjective appraiser judgement, and also to the fact that appraisals are typically made only infrequently.

Another method of obtaining the necessary data for empirical analysis is to use actual market transaction return data from stock market quoted companies (e.g. equity or mortgage REITs in the US and property companies in the UK). These series will, by definition, reflect the amount that the market is willing to pay for an investment in real estate. However, a characteristic of real estate return data from market transactions is that, as well as reflecting market movements in the property sector, they will also be subject to general stock market influences. McCue and Kling (1994) argue that as a consequence, this phenomenon might lead REITs to overstate the variability of true real estate market returns. King (1966) suggests that $31 \%$ of the movements in REITs about their mean values could be attributed to general stock market movements. It appears therefore appropriate that the study of the determinants of real estate returns should make use of returns data net of general stock market influences.

In order to purge real estate returns (transactions data) of their general stock market influences, a typical strategy is to regress the data series on the stock market index, saving the residuals. Under the usual classical assumptions, these residuals should be orthogonal to the general stock market returns, and hence these should form the basis for all subsequent analysis, as McCue and Kling (1994) suggest. The linear relationship has also been assumed by Lizieri 
and Satchell (1997), who examined the possibility of causality between stock market and property market returns for the UK. They find significant linear Granger causality from equity returns to property returns. However, although this orthogonalization has now become commonplace, researchers seem not to have considered whether this step is truly sufficient to purge real estate returns of general market effects. In particular, there might exist a nonlinear causal relationship from the market to real estate returns, which would imply that the residuals still contain unmodeled market influences.

This paper uses both US and UK real estate return data to investigate whether such a nonlinear relationship does indeed exist, rendering a linear orthogonalization insufficient. The remainder of this paper is organised as follows. Sections two and three give a description of the data and the methodology employed respectively. Section four discusses the results obtained and offers some analytical comments, while section five concludes.

\section{Data}

The data used in this study are monthly data on REITs in the US, obtained from NAREIT, and the Standard and Poors Composite Index. The UK data are the FTA Property Sector Index and the FTA All Share Index (hereafter FTAPSI and FTAS respectively). The latter three series are obtained from Datastream, and all span the period February 1972 until December $1993^{\mathrm{ii}}$, giving a total of 263 observations. All four series are converted into a set of $\log$ price relatives, which can be interpreted as continuously compounded percentage changes.

\section{Methodology}

In order to remove any traces of linear autoregressive or lagged dependencies of the REIT or the FTAPSI on the market index, a VAR is estimated separately for the US and the UK data. The number of lags of each variable to use in the VAR is determined using Akaike's, Schwarz's Bayesian and the Hannan-Quinn information criteria ${ }^{\text {iii }}$. Of the three criteria, Schwarz's Bayesian is the only one which is strongly consistent, and hence will asymptotically deliver the correct number of lags. Letting $r p_{t}$ and $r m_{t}$ denote the return on the property index and the market index respectively, the VAR can be written as 


$$
\left[\begin{array}{c}
r p_{t} \\
r m_{t}
\end{array}\right]=\left[\begin{array}{l}
a_{0} \\
a_{1}
\end{array}\right]+\sum_{i=1}^{p}\left[\begin{array}{ll}
b_{00 i} & b_{01 i} \\
b_{10 i} & b_{11 i}
\end{array}\right]\left[\begin{array}{c}
r p_{t-i} \\
r m_{t-i}
\end{array}\right]+\left[\begin{array}{l}
u_{0} \\
u_{1}
\end{array}\right]
$$

where $p$ is the number of lags of each variable in each equation of the VAR.

The nonlinear Granger causality test is employed on the residuals from the property return equations from the VARs. The test, which can be considered an extension of the BDS test (Brock et al., 1996), is essentially due to Baek and Brock (1992). It uses the concept of the correlation integral based upon the closeness of points in hyperspace. A rearrangement of the test can be viewed as a nonlinear test for Granger causality. This is an important generalisation, for there is no reason why causality should be of the linear type, and it is likely that linear Granger causality tests will have low power against many types of nonlinear causality (Brock, 1991).

A further modification which improves the small sample properties of the test and relaxes the assumption that the series to which the test is applied are independently and identically distributed, is due to Hiemstra and Jones (1994). In particular, the original Baek and Brock test is over-sized in finite samples. Results of Monte Carlo simulations in Hiemstra and Jones (1993) also show that their modified test is robust to the presence of structural breaks in the series and contemporaneous correlations in the errors of the VAR model used to filter out linear cross- and autodependence.

Now let $X_{t}$ and $Y_{t}$ denote the residuals from the VAR equations for the real estate and stock index equations respectively and let $X_{t}^{m}, X_{t-L x}^{L x}, Y_{t-L y}^{L y}$ denote a lead vector for $X$ of length $m$, and lag vectors for $X$ and $Y$ of length $L x$ and $L y$ respectively, i.e.

$$
\begin{array}{lll}
X_{t}^{m}=\left(X_{t}, X_{t+1}, \ldots, X_{t+m-1}\right), & m=1,2, \ldots & t=1,2, \ldots \\
X_{t-L x}^{L x}=\left(X_{t-L x}, X_{t-L x+1}, \ldots, X_{t-1}\right), & L x=1,2, \ldots & t=L x+1, L x+2, \ldots \\
Y_{t-L y}^{L y}=\left(Y_{t-L y}, Y_{t-L y+1}, \ldots, Y_{t-1}\right), & L y=1,2, \ldots & t=L y+1, L y+2, \ldots
\end{array}
$$

Then, following Hiemstra and Jones (1994), for given values of $m, L x$, and $L y$ all $\geq 1$ and $e>0$, if $Y$ does not strictly Granger cause $X$ (either in a linear or nonlinear sense), then we can write 
$\operatorname{Pr}\left(\left\|X_{t}^{m}-X_{s}^{m}\right\|<e \mid\left\|X_{t-L x}^{L x}-X_{s-L x}^{L x}\right\|<e,\left\|Y_{t-L y}^{L y}-Y_{s-L y}^{L y}\right\|<e\right)=\operatorname{Pr}\left(\left\|X_{t}^{m}-X_{s}^{m}\right\|<e\left\|X_{t-L x}^{L x}-X_{s-L x}^{L x}\right\|<e\right)$

where $\operatorname{Pr}(\bullet)$ denotes a probability measure and $\|\bullet\|$ denotes a distance measure (in this case the supremum norm), and $e$ denotes a fixed distance used to determine whether the two points are "close" in $m$-dimensional space or not. Hence non-Granger causality implies that the probability that two arbitrary lead vectors of length $m$ are within a distance $e$ of each other is the same conditional upon the two lag vectors of $\left\{X_{t}\right\}$ being within a distance $e$ of each other and the two lag vectors of $\left\{Y_{t}\right\}$ being within a distance $e$ of each other, and conditional upon the lag vectors of $\left\{X_{t}\right\}$ only being within a distance $e$ of each other. In other words, no Granger causality means that the probability that the lead vectors are within distance $e$ is the same whether we have information about the distances between the $\left\{Y_{t}\right\}$ lag vectors or not.

The conditional probabilities in (2) can be expressed as ratios of a joint and marginal probabilities. Thus

$$
\frac{\operatorname{Pr}\left(\left\|X_{t}^{m}-X_{s}^{m}\right\|<e,\left\|X_{t-L x}^{L x}-X_{s-L x}^{L x}\right\|<e,\left\|Y_{t-L y}^{L y}-Y_{s-L y}^{L y}\right\|>e\right)}{\operatorname{Pr}\left(\left\|X_{t-L x}^{L x}-X_{s-L x}^{L x}\right\|<e,\left\|Y_{t-L y}^{L y}-Y_{s-L y}^{L y}\right\|>e\right)}=\frac{\operatorname{Pr}\left(\left\|X_{t}^{m}-X_{s}^{m}\right\|<e,\left\|X_{t-L x}^{L x}-X_{s-L x}^{L x}\right\|<e\right)}{\operatorname{Pr}\left(\left\|X_{t-L x}^{L x}-X_{s-L x}^{L x}\right\|<e\right)}
$$

Whether the probability in (3) holds can evaluated by calculating a set of four correlation integrals, defined later:

$$
\frac{C 1(m+L x, L y, e)}{C 2(L x, L y, e)}=\frac{C 3(m+L x, e)}{C 4(L x, e)}
$$

Letting $\left\{x_{t}\right\}$ and $\left\{y_{t}\right\}$ denote the actual realisations of the process and $I(A, B, e)$ denoting an indicator function which takes the value 1 if the vectors $A$ and $B$ are within a distance $e$ of each other and zero otherwise and noting that the properties of the supremum norm allow us to write $\operatorname{Pr}\left(\left\|X_{t}^{m}-X_{s}^{m}\right\|<e,\left\|X_{t-L x}^{L x}-X_{s-L x}^{L x}\right\|<e\right)$ as $\operatorname{Pr}\left(\left\|X_{t-L x}^{m+L x}-X_{s-L x}^{m+L x}\right\|<e\right)$, then the estimates of the correlation integrals in (4) can be expressed as

$C 1(m+L x, L y, e, n) \equiv \frac{2}{n(n-1)} \sum_{t<s} \sum I\left(x_{t-L x}^{m+L x}, x_{s-L x}^{m+L x}, e\right) \cdot I\left(y_{t-L y}^{L y}, y_{s-L y}^{L y}, e\right)$

$C 2(L x, L y, e, n) \equiv \frac{2}{n(n-1)} \sum_{t<s} \sum I\left(x_{t-L x}^{L x}, x_{s-L x}^{L x}, e\right) \cdot I\left(y_{t-L y}^{L y}, y_{s-L y}^{L y}, e\right)$ 
$C 3(m+L x, e, n) \equiv \frac{2}{n(n-1)} \sum_{t<s} \sum I\left(x_{t-L x}^{m+L x}, x_{s-L x}^{m+L x}, e\right)$

$C 4(L x, e, n) \equiv \frac{2}{n(n-1)} \sum_{t<s} \sum I\left(x_{t-L x}^{L x}, x_{s-L x}^{L x}, e\right)$

for $t, s=\max (L x, L y)+1, \ldots, T-m+1, \quad n=T+1-m-\max (L x, L y)$.

Under the null hypothesis that $\left\{Y_{t}\right\}$ does not Granger cause $\left\{X_{t}\right\}$, then Hiemstra and Jones (1994, appendix) show that the test statistic $\sqrt{n}\left(\frac{C 1(m+L x, L y, e, n)}{C 2(L x, L y, e, n)}-\frac{C 3(m+L x, e, n)}{C 4(L x, e, n)}\right)$ is asymptotically distributed as a normal variate with mean zero and variance that is a complicated function of $(m, L x, L y, e, n)$. The appropriate values of the user-adjustable parameters are determined based upon a set of Monte Carlo simulations in Hiemstra and Jones (1993), which recommends the use of $m=1$, and $L x=L y=1,2,3$, or 4, that is a lead of only one step and up to four lags of the series, with the number of lags of $x$ and $y$ always equal. Also, they suggest setting the distance cut off, $e$, as between one half and twice the standard deviation of the actual data being tested for causality.

\section{Results}

Table 1 gives the number of lags of each variable selected by SBIC in the VARs for the US and the UK together with the minimised value of the criterion in each case. It is clearly evident that there is little linear structure in the US returns series for either the property sector or the market as a whole. This is demonstrated by the fact that the number of lags of both the REITs and the S\&P 500 chosen for the S\&P 500 as the dependent variable is zero and for the REITs as dependent variable, it is 1 and 0 respectively. The same is not true for the UK VAR, however, where Schwarz's criterion, which embodies a very stiff penalty term for including extra lags, chooses 3 lags of the FTAS and 1 of the FTA property returns for the FTAS as dependent variable, and 5 lags of FTA property and 1 lag of FTAS for FTAPSI as dependent variable.

Table 1: VAR Lag-Lengths Chosen by Schwarz's Criterion 


\begin{tabular}{cccc}
\hline VAR Dependent Variable & Lag Length Selected (of variable) & $\begin{array}{c}\text { Minimised Value } \\
\text { of the Criterion }\end{array}$ \\
\hline S \& P 500 Returns & 0 (S \& P) & 0 (REIT) & 791.77 \\
REIT Returns & 1 (REIT) & 0 (S \& P) & 739.00 \\
FTA All-Share Returns & (FTAS) & 1 (FT Prop) & 1008.19 \\
FTA Property Returns & 5 (FT Prop) & 1 (FTAS) & 1147.56 \\
\hline
\end{tabular}

The results for estimation of the test statistics using 1,2,3, or 4 lags of $x$ and $y$ and $e / \sigma$ of $0.5,1$, and 2 are given in tables 2 and 3 for the US and UK data respectively. The results for the US are highly conclusive: for all combinations of the user-adjustable parameters, there is no evidence of nonlinear causality from equity markets to the REITs. For the UK, however, we do find some suggestion of nonlinear causality. Using 4 lags, there is significant evidence for nonlinear relationships at the $5 \%$ level for the distance cut off set at one half, once or twice the standard deviation of the data, although, as for the US data, there is little evidence of nonlinear relationships for most values of the user-defined parameters.

Table 2: Nonlinear Granger Causality Tests Results for US Data

\begin{tabular}{|c|c|c|c|c|}
\hline \multirow[b]{2}{*}{$\varepsilon / \sigma$} & \multicolumn{4}{|c|}{ Lag Lengths } \\
\hline & 1 & 2 & 3 & 4 \\
\hline 0.5 & $\begin{array}{c}-0.056 \\
(-1.097)\end{array}$ & $\begin{array}{c}-0.0034 \\
(-0.401)\end{array}$ & $\begin{array}{l}0.0034 \\
(0.329)\end{array}$ & $\begin{array}{c}-0.0049 \\
(-0.436)\end{array}$ \\
\hline 1 & $\begin{array}{c}-0.0049 \\
(0.678)\end{array}$ & $\begin{array}{l}-0.0069 \\
(-0.516)\end{array}$ & $\begin{array}{l}0.0001 \\
(0.004)\end{array}$ & $\begin{array}{l}0.0034 \\
(0.122)\end{array}$ \\
\hline 2 & $\begin{array}{l}-0.0077 \\
(-0.749)\end{array}$ & $\begin{array}{l}-0.0413 \\
(-1.812)\end{array}$ & $\begin{array}{l}-0.0685 \\
(-0.995)\end{array}$ & $\begin{array}{l}0.0029 \\
(0.232)\end{array}$ \\
\hline
\end{tabular}

Another finding of this investigation is the existence of a weak lead / lag (both linear and nonlinear) relationship between the general market and property indices for the UK. But why might we expect such a lead-lag relationship to exist at all? In particular, since equity market indices and equity-based property sector indices are likely to have a number of common causal factors, one might anticipate a strong positive contemporaneous relationship, how can we explain the fact that a lead-lag relationship exists for the UK? Lizieri and Satchell (1997) provide a number of possible explanations, perhaps the most important being institutional inertia in the processing of information in the underlying real estate market. This would suggest that real estate indices might lag the rest of the market.

Table 3: Nonlinear Granger Causality Tests Results for UK Data 


\begin{tabular}{ccccc}
$\varepsilon / \sigma$ & 1 & 2 & 3 & 4 \\
\hline 0.5 & 0.0083 & 0.0036 & 0.0086 & 0.0120 \\
& $(1.617)$ & $(0.661)$ & $(1.490)$ & $(2.209)^{* *}$ \\
1 & 0.0098 & 0.0043 & 0.0198 & 0.0329 \\
& $(1.196)$ & $(0.477)$ & $(1.717)^{*}$ & $(2.248)^{* *}$ \\
2 & 0.0080 & 0.0038 & 0.0177 & 0.0278 \\
& $(0.807)$ & $(0.195)$ & $(0.387)$ & $(2.056)^{* *}$ \\
\hline
\end{tabular}

Note: $*$ and $* *$ denote significance at the $10 \%$ and $5 \%$ levels respectively.

\section{Conclusions}

The examination of economic and other forces that various authors have considered to explain the variation in real estate returns requires that stock market effects are removed from the returns series. This paper provides a study of the validity of the assumption that the relationship between overall market returns and real estate returns is linear. In particular the paper sought to examine whether a linear orthogonalization is sufficient to remove equity-market effects from real estate returns for the US and the UK. This is important to real estate analysts since evidence of nonlinearities in this relationship would be suggestive of stock market influences on real estate returns which have not been removed.

There seems to be very little (or no) evidence of any sort of dependence in the US REIT series, which may perhaps imply that US real estate returns reflect overall underlying market information more promptly and therefore more efficiently. The results for the UK are qualitatively different since there is some evidence of nonlinear relationships. Although the results only indicate a weak nonlinear relationship between the FT All Share Index and the FTA Property Sector Index, analysts should consider that an investigation assuming linearities may not fully extract the overall stock market influences from real estate returns. A plausible explanation for this finding is that economic and corporate information is reflected in the FTAS index in a way which differs from the manner in which the FTAPSI encapsulates economic and real estate market-related information. This may arise from the presence of institutional factors and uncertainties in the property business environment which inhibit flexible and speedy adjustment in the returns of the traded assets. These rigidities in the market are also considered to be the cause of the observed lead-lag relationship between the two indices in the UK. 
The issues that the present study examined and the results obtained could motivate further research in this subject area in a number of ways. First, the relationship between stock market returns and real estate returns could be examined in the context of other countries for the production of comparative results which may prove useful to international property analysts and investors. In particular, this research could examine the hypothesis that there exist stronger nonlinear relationships in more tightly regulated markets. Second, the methodology deployed in this paper can be used to study the relationship between filtered real estate returns series and the economic, equity and bond market variables which have been identified as major influences on stock market returns. Finally, it should also be noted that the results are likely to be sensitive to the size of the sample. The monthly sample used in this study contains a little under 300 observations (although it is at least as large as that used by the vast majority of empirical researchers in this area), so that even if nonlinear relationships are present, the tools may lack the power to detect them with such a paucity of information. As longer data series become available, this methodology will become more robust in identifying nonlinearities in the relationships between the returns series under examination.

\section{Acknowledgements}

The authors would like to thank Craig Hiemstra for generously providing his C-code for calculating the test statistics, and also for helpful discussions. The usual disclaimer applies.

\section{References}

Baek, E. and Brock, W. A (1992) Nonparameteric Test for Independence of a Multivariate Time Series, Statistica Sinica 2, 137-156

Brock, W.A. (1991) Causality, Chaos, Explanation, and Prediction in Economics and Finance, in Casti, J. and Karlqvist (eds.) Beyond Belief: Randomness, Prediction and Explanation on Science CRC Press, Boca Raton, Florida

Brock, W.A., Dechert, W.D., Scheinkman, J.A. and LeBaron, B. (1996) A Test for Independence Based on the Correlation Dimension, Econometric Reviews 15(3), 197-235

Chan, K.C., Hendershott, P.M., and Sanders, A. (1990) Risk and Return on Real Estate: Evidence from Equity REITs Journal of the American Real Estate and Urban Economics Association 18(4), 431-452

Geltner, D. (1989) Estimating Real Estate's Systematic Risk from Aggregate Level Appraisal-Based Returns Journal of the American Real Estate and Urban Economics Association 17(4), 463-481

Gyourko, J. and Keim, D.B. (1992) What Does the Stock Market tell us about Real Estate Returns? Journal of the American Real Estate and Urban Economics Association 20, 457-485 
Hiemstra, C. and Jones, J.D. (1994) Testing for Linear and Nonlinear Granger Causality in the Stock Price-Volume Relation, Journal of Finance 49(5), 1639-1664

Hiemstra, C. and Jones, J.D. (1993) Some Information Relating to the Finite Sample Properties of the Modified Baek and Brock Nonlinear Granger Causality Test, Working Paper, University of Strathclyde and Securities and Exchange Commission

King, B.F. (1966) Market and Industry Factors in Stock Price Behaviour Journal of Business 39, 139-190

Lizieri, C. and Satchell, S. (1997) Interactions Between Property and Equity Markets: An Investigation of Linkages in the UK 1972-1992 Journal of Real Estate Finance and Economics 15(1), 11-26

McCue, T.E. and Kling, J.L. (1994) Real Estate Returns and the Macroeconomy: Some Empirical Evidence from Real Estate Investment Trust Data, 1972-1991 Journal of Real Estate Research 9(3), 277-287

\footnotetext{
i These two acronyms stand for National Council of Real Estate Investment Fiduciaries and Jones Lang Wootton respectively.

ii The method of calculating the UK property sector index changes substantially after the end of 1993, and hence more recent data cannot be validly combined with previous vintages. In this study, we therefore considered it appropriate to terminate all the samples on this date so that coherent cross-country comparisons can be made. iii Only results for Schwarz's criterion are shown for the sake of brevity, although a full appendix containing all results and a summary of the number of lags chosen by each of the criteria is available from the authors upon request. In any case, the results for lag lengths chosen using the other criteria are not qualitatively different.
} 